\title{
PROYECCIONES DEL LEGADO MINERO-INDUSTRIAL EN LA PROVINCIA DE CHAÑARAL, REGIÓN DE ATACAMA, CHILE*
}

\author{
PROJECTIONS OF MINING-INDUSTRIAL HERITAGE IN THE PROVINCE \\ OF CHAÑARAL, ATACAMA REGION, CHILE
}

\begin{abstract}
Mauricio Lorca**
La provincia de Chañaral posee una larga tradición minera que ha significado la configuración de un territorio asociado a esa actividad y una profunda monodependencia económica. Actualmente el área enfrenta un complejo escenario ante el inminente cese de faenas de las dos explotaciones en las que descansan la economía y el empleo. El presente artículo explora las posibilidades que tiene el legado minero-industrial para, además de cumplir una función simbólica, constituirse en un recurso que permita a sus habitantes continuar proyectándose al futuro.
\end{abstract}

Palabras claves: Diversificación económica, gestión del territorio, minería, patrimonio industrial, turismo.

Chañaral Province has a long mining tradition which has meant setting up a territory associated with that activity and thus a mono-productive economy. Currently, the area is facing a complex scenario due to the imminent cessation of the two mines on which economy and employment rely. This article explores the possibilities of the mining-industrial legacy to not only play a symbolic function, but to constitute a resource that enables people to project their future.

Key words: Economic diversification, territory management, mining, industrial heritage, tourism.

\section{Introducción}

La provincia de Chañaral es un espacio desértico ubicado al norte de la Región de Atacama; político-administrativamente se divide en dos comunas (Chañaral y Diego de Almagro) y posee una población mayoritariamente urbana de 27.216 habitantes ${ }^{1}$ (Figura 1). La ocupación y la estructuración de este territorio como tal, encuentran su origen por la década de 1830 en un ciclo de expansión económica que el país emprendió entre esos años y fines de la década de 1870 , basado en la exportación de plata, cobre y, también, trigo (Cariola y Sunkel 1982). Durante ese período esos minerales representaron "entre la mitad y las dos terceras partes del valor total de las exportaciones del país y la más importante exportación en dicho sector correspondió al metal rojo, especialmente la de cobre fundido o refinado que aumentó más de diez veces entre 1844 y 1878" (Bravo 2009:45).

Para que esto ocurriera se conjugaron dos sucesos: la introducción en 1831 de hornos de reverbero que significaron el incremento de la producción cuprífera mediante fundición y el descubrimiento de las minas de plata de Chañarcillo, en 1832, y Tres Puntas, en 1848. Ambos eventos significaron para el área conocida como Norte $\mathrm{Chico}^{2}$ la inauguración de numerosas fundiciones de cobre, la construcción y la progresiva extensión del ferrocarril y la creación de talleres y maestranzas. Es decir, durante esta época el país presenció la instalación de una "vanguardia industrial" directamente asociada a la industria de herramientas, repuestos y bienes de capital que la minería del cobre, la plata y, luego, el salitre requirieron entre 1850 y 1914 (Ortega 1981; Pinto y Ortega 1990; Valenzuela 1995).

De este modo, esos minerales se constituyeron en la principal fuente de riqueza pública y privada del siglo XIX, permitiendo que Chile se modernizara y consolidara como república soberana y que el mercado nacional comenzara su integración a la economía mundial gracias al aumento del comercio internacional (Cariola y Sunkel 1982; Pinto y Ortega 1990; Ortega 2005). Asimismo, esos procesos permitieron que, por un lado, emergiera una elite empresarial que formó y consolidó sus fortunas alrededor de la minería, el comercio y las finanzas (Nazer 2000). Y, por

\footnotetext{
* Resultado de investigación financiada por el Sistema Becas-Chile y CONICYT.

** Universidad Autónoma de Chile, Santiago, Chile. Correo electrónico: maurolorca@ gmail.com
} 


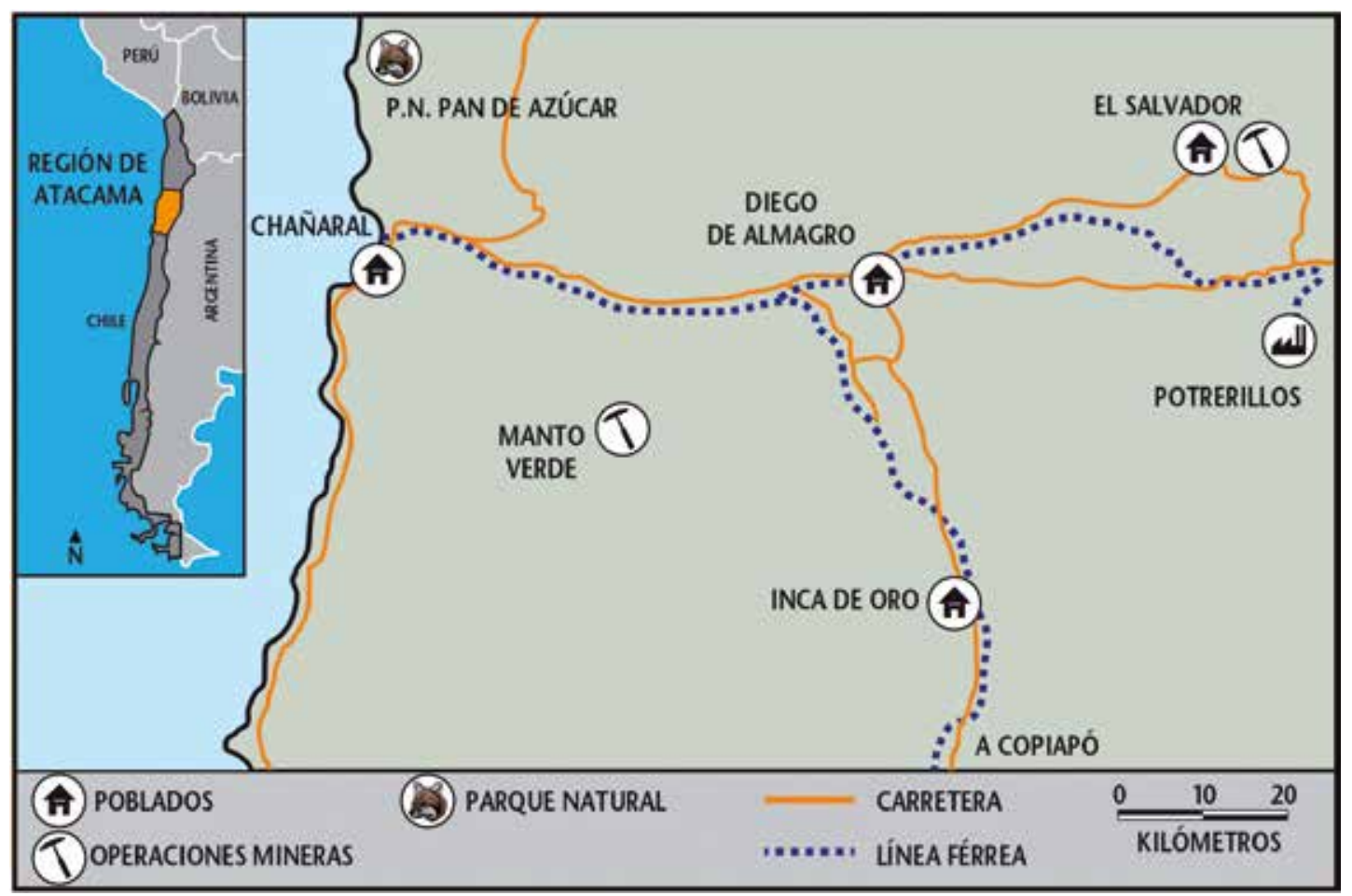

Figura 1. Mapa de la provincia de Chañaral. Elaboración propia.

otro, que se introdujeran al interior de la sociedad nacional relaciones laborales de corte capitalista que alteraron los patrones básicos de identidad y comportamiento de los trabajadores y que el capital chileno comenzara progresivamente a expandirse hacia la provincia boliviana de Antofagasta y, en menor medida, también a la peruana de Tarapacá (Salazar 1989; Illanes 1990, 1992; Godoy 2012; Godoy y González 2013; entre otros).

El resultado de esta etapa de desarrollo minero se tradujo para el Norte Chico en un notable crecimiento de la población que, entre 1835 y 1865, se duplicó; la emergencia de una clase acomodada, la implementación del ferrocarril, plantas procesadoras e instalaciones portuarias y el progreso social, cultural, político y económico de la ciudad de Copiapó (Treutler 1958; Sayago 1973 [1874]; Guajardo 2007, etc.).

Sin embargo, a fines de la década de 1870 la "edad de oro" de la minería del área entró en una coyuntura crítica para, a partir de ese momento, oscilar entre ciclos de breve bonanza y prolongadas crisis asociadas al precio internacional de los metales, básicamente del cobre, y una práctica minera anclada a una historia y una cultura propias que han entorpecido que la pequeña y la mediana minería se ajusten a los cambios en las condiciones de producción y oferta que impone el mercado internacional (Pederson 2008 [1966]; Ortega 2010, 2012).

Esta trayectoria histórica se confirma al observar el complejo escenario que hoy enfrenta la provincia de Chañaral. Actualmente las dos únicas explotaciones pertenecientes a la gran minería y principales fuentes económicas y de empleo del área detendrán sus faenas en los próximos años: la mina Manto Verde de la empresa Anglo American programa el agotamiento de sus reservas para el $2017^{3}$ y la División Salvador de la Corporación Nacional del Cobre (CODELCO) proyecta actividades hasta el 2016 y, bajo ciertas condiciones de mercado, hasta el $2021^{4}$. Sin embargo, el cambio en la forma de explotación de una de las tres minas que la componen duplicaría su producción permitiendo eventualmente prolongar sus operaciones por otros 20 años 5 . 
Este escenario se ve agravado debido a que la minería del área se limita a la cuprífera; el sector de la mediana minería es inexistente y porque Manto Verde y la División Salvador corresponden a las expresiones más débiles de la gran minería nacional: la primera es una de las minas más pequeñas del sector y, la segunda, la más deficitaria de CODELCO. Esto se traduce en que ninguna ha sido capaz de desarrollar actividades asociadas y que, al contrario, la gran minería ha dejado un colosal pasivo ambiental que ha impedido el desarrollo de otros sectores económicos en la provincia ${ }^{6}$ (Gobernación Provincial de Chañaral et al. 2006).

Este escenario hace imperioso diversificar la estrecha base productiva de esta unidad territorial, reconociendo sus recursos y oportunidades. ¿Pueden los restos dejados por la actividad minera ser un aporte para resolver los desafíos que hoy enfrenta esta provincia? ¿Es la aplicación de modelos de puesta en valor patrimonial que se demuestran exitosos en otras partes del mundo una posibilidad para ampliar la economía local? Este artículo explora la posibilidad de que la activación del legado minero-industrial territorial se constituya en un factor de desarrollo para la provincia de Chañaral. Para ello se revisa la significancia que la minería ha tenido en la construcción y la articulación de este espacio territorial y se describen y examinan las acciones orientadas a desarrollar en el área actividades turísticas asociadas a su legado minero. Esto se presta para proponer que el legado mineroindustrial provincial, al proporcionar una visión integrada y abierta del territorio, puede constituirse en un factor de desarrollo como herramienta de planificación local. ${ }^{7}$

\section{La construcción de la Provincia de Chañaral como Territorio Minero}

La interacción que con el tiempo ha tenido el ser humano y el medio ambiente en la provincia de Chañaral ha configurado un territorio asociado al trabajo que confiere valor histórico y testimonial a muchos de los elementos que lo componen. En efecto, la trayectoria histórica provincial está íntimamente asociada a la minería, pudiéndose eslabonar su desarrollo mediante tres hitos: su configuración territorial desde la década de 1830; el comienzo de la explotación industrial de Potrerillos por la década de 1910 y la inauguración, en 1959, del complejo minero-industrial de El Salvador.

\section{La penetración del desierto}

Hasta la década de 1830 los espacios geográficos ubicados al norte de la ciudad de Copiapó habían permanecido prácticamente vírgenes debido a las limitaciones que imponía su condición desértica. Sin embargo, a partir de esa década el área comenzó a ser explorada por naturalistas y cateadores que, con fines científicos y económicos, registraron y sondearon las riquezas de un espacio que hasta entonces era considerado adverso, estéril e inhóspito (Godoy 2012; Godoy y González 2013).

En 1827 fue descubierto el mineral Las Ánimas y asociado a él, en 1833, se fundó el puerto de Chañaral. A partir de entonces se descubrieron y comenzaron a explotar distintos yacimientos que configuraron diferentes distritos mineros. Esas faenas transformaron el desierto en territorio, expandiéndolo económica y demográficamente e integrándolo al resto del país. Durante la década de 1860 se instalaron en el puerto de Chañaral dos fundiciones de cobre y, posteriormente, una tercera. De forma paralela, las líneas ferroviarias fueron extendiéndose progresivamente por todo el territorio para conectar las áreas productoras de minerales con los puertos y el transporte de pasajeros (Rubio 2009).

De acuerdo con Rubio (2010:200), durante esa época se configuró un territorio "cobrero y periférico" que desarrolló una monodependencia que tomó la forma de grandes compañías, pero que, sobre todo, se concentró en "pequeñas unidades y minería propiamente pirquinera, trabajada casi siempre por pequeños propietarios o por actores populares propiamente tal" (Rubio 2009:269).

A partir de la década de 1870 la minería tradicional ya demostraba su fragilidad afectando gravemente al territorio de Chañaral que hasta bien entrado el siglo XX "continuaba insistiendo en la explotación del metal rojo, sin innovaciones de importancia en el ámbito de la extracción del mineral y lo más importante, careciendo de otras 'salidas' de carácter económico como la agrícola o de servicios" (Rubio 2010:200). Esa situación de estancamiento no se revertiría hasta la inauguración de la gran minería cuprífera en la zona.

\section{Capitales estadounidenses en Potrerillos}

De acuerdo con Bravo (2009), entre 1860 y 1880 Chile fue el primer productor de cobre a nivel mundial, representando el $42,3 \%$ de las 
exportaciones nacionales y el $10 \%$ de las entradas fiscales. La llegada de la gran minería cuprífera al país significó que el cobre recuperara el rol que había tenido durante esos años.

La llegada de empresas estadounidenses a Chile durante la primera década del siglo XX se fundamentó en el enorme capital y las condiciones técnicas que poseían y en las favorables condiciones que ofrecía el Código de Minería de la época. En 1919 se iniciaron los trabajos para explotar el mineral de Potrerillos que, ubicado a unos $125 \mathrm{~km}$ al oriente del puerto de Chañaral y a $2.800 \mathrm{msm}$, rápidamente se convirtió en el motor económico del área.

Para llevar a cabo su explotación se construyeron, por una parte, una importante red industrial compuesta por una planta de sulfuros y otra de lixiviación, un puerto de embarque y una planta termoeléctrica en Barquitos (a ocho km al sur de Chañaral) y un tendido ferroviario que unió ambos puntos. Y, por otra, se erigió un asentamiento urbano que llegó a albergar diez mil personas entre trabajadores y sus familias, el que además de contar con viviendas y edificios de equipamiento, fue dotado de toda la infraestructura urbana necesaria: plaza, escuela, iglesia, hospital, cuartel de policía, instalaciones administrativas, hotel, jardín infantil, teatro, un estadio de fútbol e incluso terrenos para la práctica de tenis y golf (Alvear 1975) (Figura 2).

A fines de la década de 1940 el yacimiento conocido como mina vieja de Potrerillos comenzó a agotarse. Ante esto y para aprovechar la infraestructura industrial existente, se iniciaron varias exploraciones y sondajes que culminaron en 1954 con el descubrimiento del yacimiento Indio Muerto a unos $20 \mathrm{~km}$ de Potrerillos. En 1959 El Salvador comenzó sus explotaciones y Potrerillos las cerró, conservando solo las operaciones pirometalúrgicas y sus instalaciones urbanas. En 1997 Potrerillos fue declarado zona saturada de contaminación por la Comisión Nacional del Medio Ambiente (CONAMA) y su campamento fue definitivamente erradicado el año 2000. Desde entonces pasó a ser un recinto industrial de CODELCO.

\section{El complejo industrial de El Salvador}

El mineral de El Salvador se ubica a $45 \mathrm{~km}$ de Potrerillos y a $2.600 \mathrm{msm}$. Al igual que ese yacimiento, El Salvador tiene asociada a su infraestructura

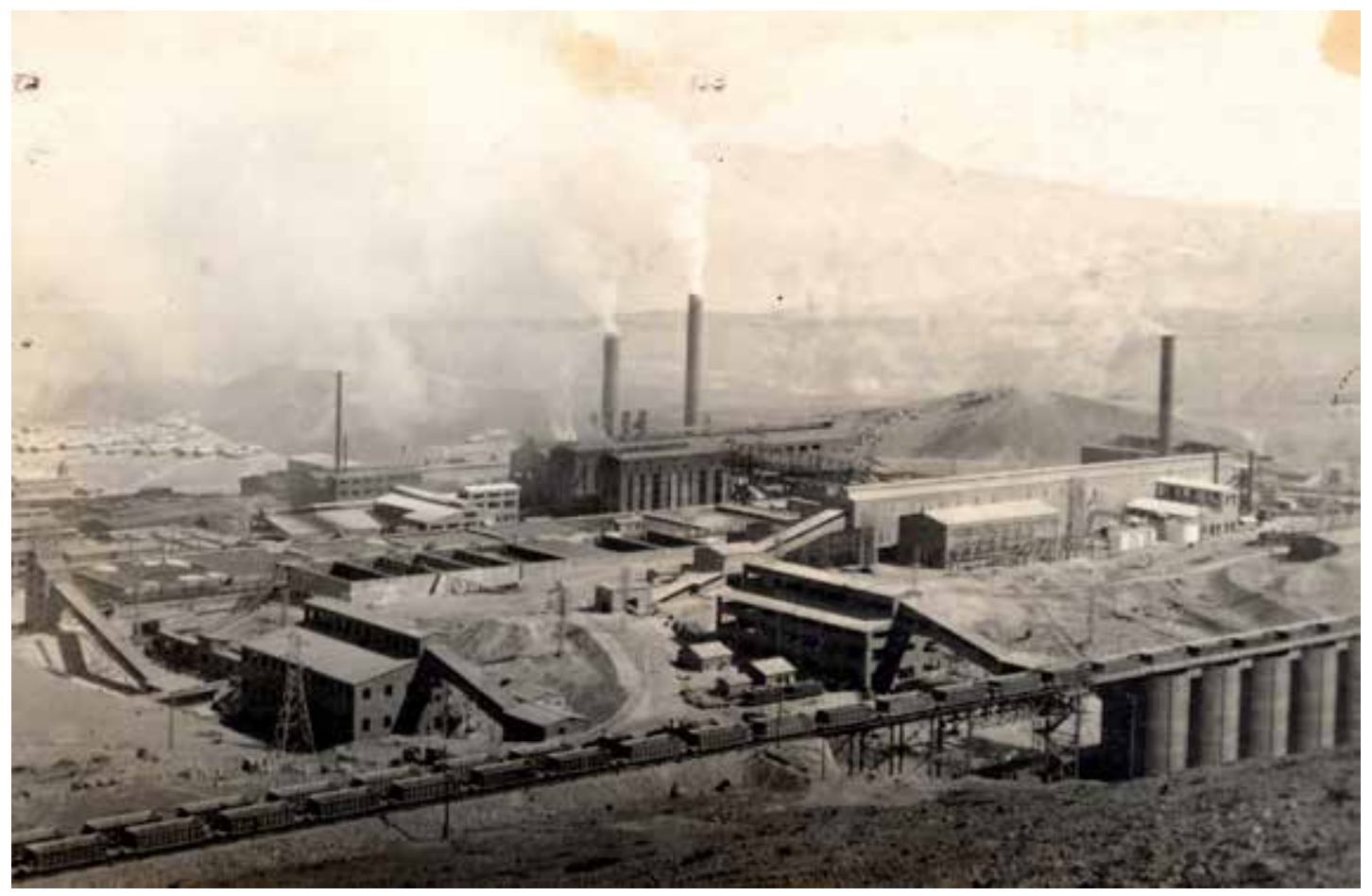

Figura 2. Potrerillos en 1927. Fuente: memoriaminera.cl 
industrial un asentamiento urbano que hoy es la última ciudad derivada del modelo company town del país (Garcés 2009) (Figura 3).

Desde la primera década de este siglo la División Salvador presenta importantes pérdidas económicas que hicieron prever el cierre de sus operaciones durante el año 2009-2010. Sin embargo, el repunte de los precios internacionales del cobre durante esa década y el notorio impacto económico que significará el cierre del mineral para la provincia de Chañaral, ha hecho que la vida útil de la explotación sea sucesivamente proyectada.

Como se puede observar, la significancia de la minería en la provincia es elocuente: las huellas que esa actividad ha dejado permiten eslabonar la construcción del territorio, exponiendo las transformaciones, las continuidades, los impactos y las formas de vida que le están asociadas. En efecto, la importancia de la industria minera en este espacio es tan significativa que puede ser concebido como un paisaje de la industrialización que, según Cruz y Español (2007:119), son "aquellos territorios que, conformados a lo largo del tiempo como consecuencia del desarrollo de actividades industriales o en relación a ellas, conservan elementos y rasgos suficientes para ilustrar las aportaciones de aquel proceso histórico".

En tal sentido, la emergencia de la noción de paisaje como interpretación colectiva del territorio tal y como es percibida por la población que lo habita, profundiza la importancia de la cultura en la definición de un espacio. Este aspecto se vio fortalecido cuando UNESCO incorporó la categoría de paisaje cultural como medio de construcción e interpretación de los territorios mediante la patrimonialización de bienes culturales existentes en su interior (Torrico y Hernández 2012).

Ahora bien, según Trachana (2011), los paisajes culturales pueden clasificarse en urbanos, rurales, arqueológicos e industriales. Los paisajes industriales son el resultado de procesos antrópicos altamente complejos cuya comprensión implica la contextualización geográfica de los procesos de industrialización, lo que, a su vez, significa la interrelación de una amplia variedad de lugares al interior de un territorio. Por esta razón, entender los restos industriales como sistemas histórica y territorialmente estructurados, permite identificar y

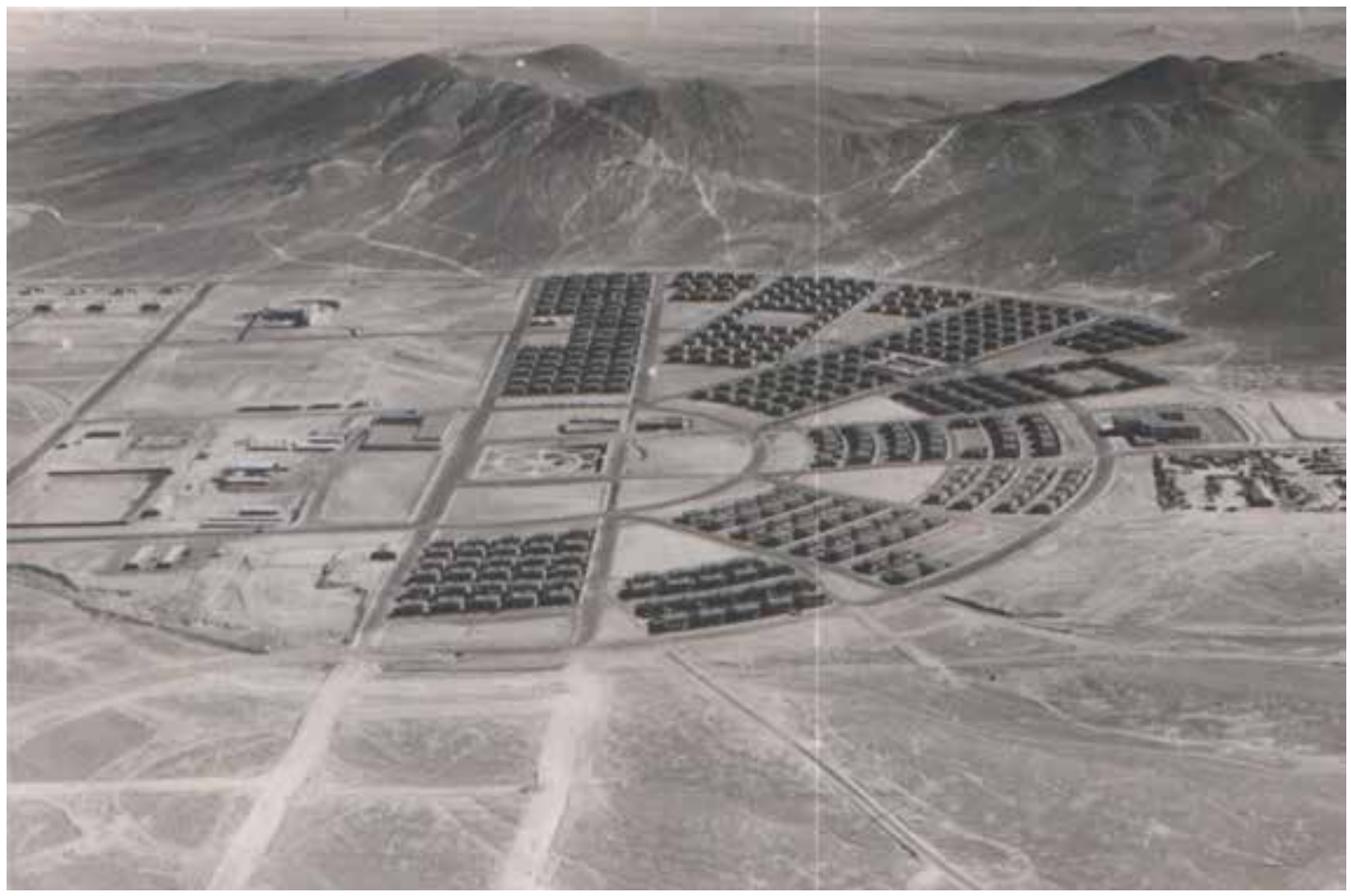

Figura 3. El Salvador en 1960. Fuente: memoriaminera.cl 
articular ciertos acontecimientos y elementos, proporcionándoles nuevos significados y valoraciones.

Por tanto, la provincia de Chañaral puede ser entendida como un territorio minero que alberga algunos bienes que pueden ser simbólicamente activados. Sin embargo, para que esas trazas y manifestaciones de raigambre minera adquieran significado y sean cabalmente entendidas, deben articularse entre sí y el entorno, contextualizándolas e interpretándolas no aisladamente, sino de forma relacional (Álvarez 2010). El resultado de esto es un conjunto patrimonial territorialmente representativo que identifica y destaca la pertenencia de sus habitantes a un espacio geográfico y cultural específico, revalorizando al territorio y los bienes existentes en él, confiriéndoles, además, la oportunidad de constituirse en recursos que pueden trascender el campo cultural.

\section{El patrimonio minero-industrial como aporte al desarrollo provincial}

Desde la década de 1970 se identifican alrededor del mundo, especialmente en Europa, la ejecución de numerosas iniciativas que-impulsadas desde el sector público, pero también desde el asociativo y el privado- apuestan por la patrimonialización y la puesta en valor de los restos de explotaciones industriales y mineras como estrategia para dinamizar economías históricamente asociadas a la industria.

Una de las contribuciones más importantes de los vestigios industriales consiste en su reocupación o reutilización en actuaciones (museos, rutas, parques patrimoniales, etc.) que compatibilizan la comprensión y la interpretación de esos elementos -conformándoles en aportes para el aprendizaje y la reflexión en términos técnicos, sociales y ambientales- con su transformación en bienes de consumo cultural para visitantes externos (Pérez y Parra 2004; Valenzuela et al. 2008; Pardo 2011; entre otros).

De esa forma, el patrimonio industrial ha ido adquiriendo un creciente protagonismo como factor de reflexión de la evolución del entorno y la identidad de un grupo e, igualmente, dentro de las políticas de planificación y las estrategias de desarrollo en espacios que enfrentan escenarios posindustriales o de cierre de faenas mineras en que es patente la necesidad de reconversión económica.

Para enfrentar los efectos críticos que el escenario posminero significará para la provincia de Chañaral, algunas instituciones públicas y privadas formularon, el año 2006, el Plan Provincial Chañaral para la Diversificación y el Desarrollo. Ese documento identifica nueve ejes productivos que podrían diversificar la economía provincial orientándola hacia el crecimiento, el desarrollo y la sustentabilidad. Entre esas propuestas está el desarrollo de un plan turístico que integre y promocione los atractivos del territorio provincial que, según ese texto, son:

\begin{abstract}
el Parque Nacional Pan de Azúcar, la playa artificial de relaves de Chañaral como muestra de desastre ecológico y el yacimiento de Gran Minería Mantoverde, todos en la comuna de Chañaral; los cultivos de desierto de Pampa Austral, el pueblo típico minero de Inca de Oro y su entorno, el observatorio astronómico de Inca de Oro, el ferrocarril de montaña de Potrerillos y los recursos de precordillera (salar de Pedernales, río y bofedales de La Ola, termas de Juncalito y otros), en la comuna de Diego de Almagro (Gobernación Provincial de Chañaral et al. 2006:18).
\end{abstract}

El desarrollo del turismo en la provincia es incipiente y sus productos están escasamente integrados y reconocidos en el mercado nacional, concentrándose en el borde costero, alrededor del Parque Nacional Pan de Azúcar situado a $30 \mathrm{~km}$ al norte de la ciudad de Chañaral. De este modo, para abordar el posicionamiento del turismo en el territorio la Corporación de Fomento de la Producción (CORFO) creó, el 2009, el Programa Territorial Integrado de Turismo Patrimonial de Recursos Naturales, Culturales y Servicios Asociados de la Provincia de Chañaral (PTI-CORFO). Así, entre ese año y el 2013 esa institución de fomento productivo tuvo como objetivos: la articulación público-privada, la generación y la difusión de proyectos turísticos estratégicos y la capacitación de recursos humanos en el área.

Si bien ese trabajo se centró fundamentalmente en las potencialidades turísticas del Parque Nacional citado, también emprendió algunas acciones encaminadas al desarrollo del turismo de intereses especiales vinculado a los vestigios mineros del territorio. ${ }^{8}$ Fundamentalmente mediante la confección de un guion turístico denominado "Provincia de Chañaral, corazón minero de Chile" (Desarrollo Turístico Sostenible 2010) y el apoyo a dos productos 
que, en el poblado de Inca de Oro, complementan la puesta en valor de la identidad y la memoria minera del lugar con el turismo de fines especiales: el museo minero-pirquinero de Inca de Oro y un recorrido turístico por las minas más atractivas del sector $^{9}$ (Figura 4). Las acciones del PTI-CORFO se orientaron entonces a dotar de señalética al circuito minero e impulsar la conformación legal de una agrupación para gestionar y ofrecer servicios turísticos en ese poblado y Diego de Almagro. Sin embargo, a pesar de la singularidad y el atractivo que esos productos exhiben y el apoyo institucional recibido para fortalecerlos, es patente que la distancia que separa a Inca de Oro de los centros urbanos regionales, el escaso transporte interurbano existente, la falta de servicios de alojamiento dirigidos al turismo, la limitada oferta de calidad en el sector de la restauración y el desinterés del mundo privado por invertir en turismo en la zona se convierten en obstáculos significativos que, por el momento, atentan contra la demanda turística en el lugar pero también en el resto de la provincia.
Por su parte, el guion turístico desarrollado por el PTI-CORFO alrededor de la identidad y la cultura minera provincial se vio notoriamente limitado debido a que fundamentó su propuesta en un discurso basado en fuentes históricas que, en la actualidad, no necesariamente tienen un correlato tangible y porque tampoco logró relacionar entre sí a los bienes existentes. Además, el proceso de identificación de esos elementos y el diseño de propuestas careció de suficientes espacios de participación y consenso con actores sociales locales fundamentales para el éxito de cualquier intervención territorial. Esto significó la aparición de conflictos con, por ejemplo, el municipio de Diego de Almagro, que terminaron por obstaculizar la concreción del trabajo realizado. ${ }^{10}$

Como se aprecia, "la conversión del patrimonio en recurso y de este, a su vez, en producto turístico no es tarea fácil" (Valenzuela et al. 2008:241). Como apunta Prats (2011:250), existen solo tres situaciones que hacen que el patrimonio adquiera viabilidad turística: primero, cuando esos elementos

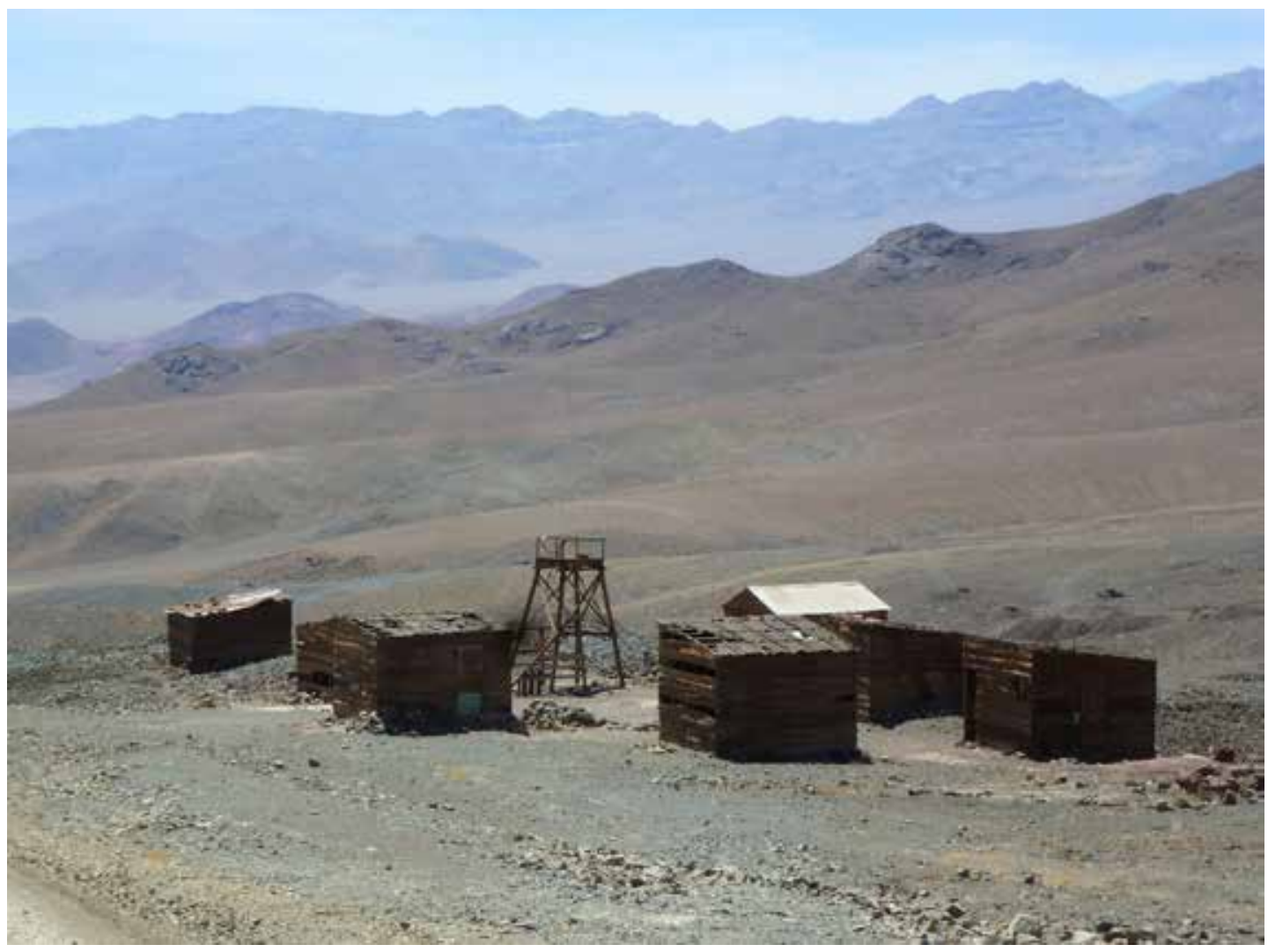

Figura 4. La Cirujana, mina del siglo XIX que forma parte de la Ruta Minera de Inca de Oro. Fotografía del autor. 
son capaces de atraer por sí mismos una cantidad de visitantes que justifique el desarrollo de infraestructura turística. Segundo, cuando esos recursos están ubicados dentro o cerca de áreas urbanas con una población que, al menos en teoría, está dispuesta a invertir y disfrutar de ellos. Tercero, cuando el patrimonio existente se ubica en destinos turísticos consolidados y que, por tal razón, cuentan con un flujo de visitantes asegurado. De lo contrario, si no cumplen ninguna de estas condiciones, las posibilidades para que los recursos patrimoniales sean económicamente sostenibles y se conviertan en un aporte al desarrollo local, son pocas.

Asimismo, no pocas veces los proyectos turísticos en torno al patrimonio acusan debilidades, omisiones, errores y riesgos, no solo en áreas periféricas como la estudiada, sino en destinos turísticos ya maduros. Además, en muchos casos, tampoco existe claridad acerca de la sostenibilidad social y económica de un proyecto patrimonial, pues no es raro que las previsiones depositadas en él rebasen sus posibilidades reales de éxito para convertirse en un aporte para el empleo y la riqueza de un lugar (Prats 2003).

En otras palabras, las posibilidades para que los vestigios mineros de características patrimoniales de la provincia de Chañaral se conviertan en un estímulo para la diversificación de su estrecha base económica son escasas y, si se opta por esa alternativa, es preciso definir claramente las aspiraciones y las posibilidades que se tienen sobre ellos. Por una parte, esto significa reconocer y valorar esos bienes mediante "una lectura actualizada, integrada y científica" que los identifique y evalúe con la ayuda de criterios que aprecien su conservación, propiedad, integridad y rentabilidad social (Álvarez 2010:24). Y, por otro, identificar las posibilidades que el territorio posee para acoger actividades turísticas en torno a ellos.

Efectivamente, como indican François y colaboradores (2006:687), al igual que la mayoría de los recursos, la construcción del patrimonio y el territorio responden a operaciones que se concretan mediante procesos de "revelación-valoración" que implican su activación o, en otras palabras, que esos recursos pasen de un estado de latencia a ser reconocidos como de utilidad colectiva. Es decir, el valor de uso que el patrimonio y el territorio pueden alcanzar estriba en que sean socialmente apropiados y pasen a formar parte de las interacciones y las sinergias de los actores sociales de un lugar.
Como menciona Capel (2014:26), generalmente ese proceso comienza por el inventariado y la catalogación de los bienes de un territorio, pues eso otorga "significado a los elementos o restos existentes y hace tomar conciencia sobre el valor del patrimonio que posee una localidad". Al respecto, es destacable la labor de investigación y difusión de la historia local que, desde hace un par de años, ejecuta el Departamento de Cultura y Turismo de la Municipalidad de Diego de Almagro. Esta se traduce en varias publicaciones acerca de la constitución y la trayectoria histórica territorial y la realización, a la fecha, de siete encuentros de historia local en que dialogan académicos, investigadores autodidactas, estudiantes y pobladores tanto de la provincia de Chañaral como de la Región de Atacama. ${ }^{11}$

Esos productos sin duda aportan material para la comprensión de un área históricamente marginal para las ciencias sociales nacionales, constituyéndose además en valiosos espacios de participación que refuerzan las capacidades de los participantes como productores de especificidad y al patrimonio y el territorio como recursos de diferenciación y caracterización colectiva. Es decir, ese trabajo representa una plataforma de sustentabilidad social para acciones dirigidas a que algunos de los elementos territoriales sean eventualmente reconocidos, interpretados, puestos en valor, exhibidos y gestionados -vale decir, patrimonializados-con la adhesión y participación de parte importante de la población local.

Asimismo, si en algún momento se decide promocionarlos turísticamente, esa misma sensibilidad seguramente facilitará la construcción de formas de gestión y toma de decisiones basadas en la participación, la cooperación, la negociación y el consenso entre los actores sociales concernidos, ajustándose de paso a las especificidades y los conflictos que puede desencadenar una activación. Al fin y al cabo, el patrimonio es un campo material y simbólico en el que no es raro se manifiesten las elecciones y los intereses políticos y económicos de los individuos que representa (García Canclini 1999; Arrieta 2010).

Por otra parte, la activación patrimonial de bienes industriales está sujeta a condiciones y desafíos específicos que deben ser especialmente considerados en el caso de la provincia de Chañaral. Entre los factores que limitan las proyecciones de ese legado en el área destacan: el deterioro que presentan debido a la falta de protección legal que 
enfrenta la casi totalidad del patrimonio provincial $\mathrm{y}$ ciertos factores estructurales que, en general, restringen seriamente las oportunidades productivas territoriales.

Como proponen varios autores (Alonso 2002; Magán 2002; entre otros), la perspectiva territorial que involucra el patrimonio industrial plantea serias dificultades para la protección de sus manifestaciones, pues

cuando las manifestaciones del patrimonio industrial definen paisajes o espacios, su protección no puede venir de la mano, exclusivamente, de las técnicas reguladas en la legislación sectorial, sino que requiere una integración y coordinación con los mecanismos de la ordenación territorial y con las políticas de desarrollo económico y social (Alonso 2002:113).

Sin duda, la escasa percepción patrimonial existente respecto de estos bienes hace que no se les considere como dignos de interés, ya sea porque son más bien recientes, porque han tenido finalidades utilitarias o porque están asociados al mundo del trabajo y, por tanto, no tienen relación con la vida personal o social (Magán 2002; Calderón 2007). A esto se añade el peligro de expolio al que permanentemente están expuestos los bienes muebles, la infraestructura y los archivos industriales cuando una mina, una fábrica o una empresa es cerrada o abandonada. Tampoco es extraño que las entidades inmateriales relacionadas al patrimonio industrial se vean constantemente amenazadas de desaparición cuando los oficios y, en general, los conocimientos y las formas de organización quedan en desuso y los depositarios de esos conocimientos desaparecen sin dejar testimonio.

Otro enorme reto para esta categoría patrimonial es la pugna existente entre intereses económicos e intereses culturales que, por lo general, se traducen en tensiones entre quienes impulsan una activación desde el mundo asociativo o el público y los propietarios de esos bienes que consideran que esas acciones y la adquisición de estatus patrimonial constituyen un atentado a sus intereses económicos. Es decir, el consentimiento y el sostén de los dueños de cualquier bien es una condición fundamental para emprender su puesta en valor.

Construir oportunidades asociadas al turismo tampoco es fácil en una zona periférica, poco poblada, totalmente dependiente de la explotación de materias primas, con una muy limitada oferta de servicios y con un bajo posicionamiento en el resto del país. Pues si bien el área demuestra una innegable especificidad y autenticidad histórica y cultural, es indiscutible que esos factores estructurales limitan las proyecciones de cualquier actividad económica ajena a la extracción de materias primas. En consecuencia, en el caso de una actuación patrimonial es preciso evaluar concienzuda y críticamente el contexto territorial definiendo su compatibilidad o incompatibilidad como soporte de actividades turísticas. Ciertamente, el territorio de estudio presenta deficiencias que deben ser corregidas: la oferta de alojamiento y restauración existentes es claramente escasa en número y calidad, el transporte interurbano es deficiente, debido a las considerables distancias que separan a la provincia de los centros urbanos regionales y del país y, además, los guías, operadores y servicios turísticos del área son también escasos y no están relacionados.

A esto debe sumarse el hecho de que las instituciones públicas encargadas de la promoción y la puesta en valor de bienes patrimoniales se demuestran débiles y poco efectivas producto de un financiamiento insuficiente y acciones limitadas, descoordinadas y poco sistemáticas; mientras que el sector privado, especialmente el sectorial, no demuestra interés en invertir y poner en valor el legado que la minería ha dejado en el área, concentrando sus acciones en donaciones de infraestructura, mobiliario, tecnología informática o actividades dirigidas al entretenimiento, pero no a proporcionar recursos que se sustenten en el tiempo, omitiendo la deuda histórica que ese sector tiene con la provincia debido al enorme daño ambiental causado. Sin embargo, lo realmente preocupante es la inexistencia de una visión integrada del territorio que impide que las acciones de desarrollo que se emprenden sean correctamente planificadas y se sustenten en el tiempo. Esto queda de manifiesto al advertir que la mayor parte de las acciones promovidas en la provincia se concentran en el sector costero, específicamente alrededor del Parque Nacional Pan de Azúcar, desdeñando las potencialidades y las necesidades del resto del espacio provincial.

\section{A modo de conclusión}

Las oportunidades y el desarrollo han sido históricamente ajenos a una unidad territorial secundaria 
y económicamente frágil como la provincia de Chañaral y que, además, no ha sabido implementar una visión integrada de su territorio, ya que, por una parte, se ha concentrado en la explotación minera $\mathrm{y}$, por otra, porque los esfuerzos que actualmente se realizan para generar nuevas oportunidades de desarrollo se centralizan en su borde costero.

Como anota Álvarez (2010:22), "la identidad de un país o de una región se construye básicamente sobre el reconocimiento del paisaje como recurso patrimonial conservando aquello que se percibe útil socialmente". En tal sentido, es cierto que el turismo está teniendo cada vez mayor protagonismo en iniciativas que otorgan nuevos sentidos y funciones a los bienes patrimoniales de un territorio y eso es una oportunidad para entender y apropiarse de un espacio mediante su representación. Sin embargo, la posibilidad de que un territorio se convierta en un lugar turístico responde a un proceso de construcción complejo y costoso que muchas veces termina prolongándose excesivamente en el tiempo y que amenaza con no responder a los anhelos depositados en él.

Eso no significa caer en el decaimiento o la falta de motivación, pues la provincia de Chañaral posee recursos con características patrimoniales sobre los cuales construir alternativas realistas que transformen los problemas en oportunidades, aunque estos deben ser activados; es decir, reconocidos y valorados por los habitantes del área. Indudablemente, uno de ellos es el vasto patrimonio de raigambre minero-industrial existente en el territorio. El patrimonio industrial proporciona una mirada que, al relacionar una variedad amplia de puntos al interior de un espacio sociogeográfico, proporciona una comprensión integrada y abierta de ese territorio realzándolo como objeto específico y de interés patrimonial. Es decir, entrega una visión espacialmente situada que profundiza la importancia de la cultura en los procesos de territorialización y, concomitantemente, del territorio en las dinámicas de patrimonialización (di Méo 1995; Yáñez 2008).

En otras palabras, patrimonio y territorio son hoy nociones indisociables y determinantes en la construcción y la interpretación de uno y otro. Esto significa para la provincia de Chañaral que el patrimonio, si bien tiene pocas posibilidades de constituirse en un aporte más o menos inmediato al desarrollo provincial mediante su integración al turismo, como indica Prats (2003:136), puede ser usado como un "instrumento integral de planificación local" que refuerce las especificidades, la autenticidad, la originalidad y ciertos aspectos territoriales que hasta ahora no han sido lo suficientemente conocidos ni valorados por el resto del país.

En efecto, en varios lugares del Norte Chico se aprecian procesos de producción patrimonial en torno a elementos asociados a la minería orientados, por un lado, a transformarlos en operadores de la identidad y la memoria en territorios específicos (como el antiguo campamento de Potrerillos). Y, por otra parte, para constituirlos en referentes simbólicos que destaquen el rol que la minería ha cumplido en el área, conformándolos en instrumentos de comprensión y acción de las sociedades regionales (como el caso del exmineral de plata de Chañarcillo y el proyecto denominado Ruta Geominera de la Región de Coquimbo) (Lorca 2015). Es decir, el patrimonio minero del Norte Chico está siendo entendido, apropiado y desarrollado como un recurso que, además de afianzar el vínculo y la cohesión social, tiene la capacidad de singularizar, agregar valor y, bajo ciertas condiciones, colaborar en el desarrollo de los territorios en los que se inserta.

Además, como destaca Ladrón de Guevara (2004:76), "la acción de 'patrimonializar' un elemento es en sí mismo un acto relevante del ordenamiento, porque se le está asignando una categoría particular de conservación o manejo que impide se le pueda manipular libremente". Por cierto, incorporar el patrimonio que alberga un espacio al ámbito de las políticas públicas permite una planificación y un ordenamiento local más integral, efectivo y sustentable para decidir e impulsar acciones mejor ajustadas a las posibilidades territoriales y las necesidades de sus habitantes.

Sin duda, actualmente existe cierto grado de valoración social y de compromiso político fundamentales para que los vestigios de la minería del área puedan convertirse en un activo que, si bien no solucionará las problemáticas que aquejan a la provincia, pueden constituirse en factor de desarrollo. Primero, proporcionando una visión unitaria al territorio provincial y, segundo, porque potencialmente sobre ese legado pueden converger modelos de educación y esparcimiento que permitan a esta unidad territorial continuar proyectándose al futuro. 


\section{Referencias Citadas}

Alonso, R.

2002 Aspectos normativos del patrimonio industrial. La ley del principado de Asturias 1/2001, de 6 de marzo de patrimonio cultural. En Patrimonio Industrial: Lugares de la Memoria. Proyectos de Reutilización en Industrias Culturales, Turismo y Museos, Varios Autores, pp. 109-128. INCUNA, Gijón, España.

Álvarez, M.Á.

2010 Patrimonio industrial, paisaje y desarrollo territorial. AREAS, Revista Internacional de Ciencias Sociales 29:21-29. Alvear, J.

1975 Nuestro cobre: Chuquicamata, El Salvador, Potrerillos, El Teniente, Enami, Mantos Blancos y Andina. Editorial Lastra S.A., Santiago, Chile.

Arrieta Urtizberea, I.

2010 El campo patrimonial y museístico: Un espacio cultural conflictivo. Revista de Dialectología y Tradiciones Populares LXV (2):303-336.

Bravo, C. G.

2009 La minería como eje dinamizador de Chile en el siglo XIX. En Chile Minero. Enami en la Historia de la Pequeña y Mediana Minería Chilena, editado por Empresa Nacional de Minería (ENAMI), pp. 45-59. Ocho Libros Editores, Santiago, Chile.

Calderón, B.

2007 Nuevos usos para el patrimonio arquitectónico industrial en Valladolid: Completar equipamientos y generar valor. Scripta Nova, Revista Electrónica de Geografía y Ciencias Sociales (1 septiembre) Vol. XI No 247. En http://www. ub.edu/geocrit/sn/sn-247.htm (2 diciembre 2014).

Capel, $\mathrm{H}$.

2014 El patrimonio: La Construcción del Pasado y del Futuro. Ediciones del Serval, Barcelona, España.

Cariola, C. y O. Sunkel

1982 La historia económica de Chile 1830-1930: Dos ensayos y una bibliografía. Ediciones Cultura Hispánica, Madrid.

Cruz, L. e I. Español

2007 Los paisajes de la industrialización. Bienes Culturales, Revista del Instituto del Patrimonio Histórico Español 7:119-131.

Desarrollo Turístico Sostenible

2010 Estudio de identidad local turística, provincia de Chañaral. Segundo informe de avance. Santiago, Chile.

François, H.; M. Hirczak y N. Senil

2006 Territoire et patrimoine: La co-construction d'une dynamique et de ses ressources. Revue d'Économie Régionale et Urbaine 5:683-700.

Garcés, E.

2009 Potrerillos, Paipote y El Salvador, ciudades del cobre en Atacama. En Chile Minero. ENAMI en la Historia de la Pequeña y Mediana Minería Chilena, editado por Empresa Nacional de Minería (ENAMI), pp. 143-159. Ocho Libros Editores, Santiago, Chile.

García Canclini, N.

1999 Los usos sociales del patrimonio cultural. En Patrimonio Etnológico. Nuevas Perspectivas de Estudio, coordinado por Encarnación Aguilar, pp. 16-33. Junta de Andalucía-Instituto Andaluz del Patrimonio Histórico, España.

Gobernación Provincial de Chañaral, Municipalidad de Diego de Almagro, Corporación Chañaral y Consejo de Desarrollo
Ciudadano de Diego de Almagro. 2006. Plan provincial Chañaral para la diversificación y el desarrollo. Chañaral, Chile.

Godoy, M.

2012 Entre la metáfora de la insularidad y la construcción de Estado nacional: El Norte Chico, 1840-1880. Diálogo Andino 40:71-82.

Godoy, M. y S. González

2013 Norte Chico y Norte Grande: Construcción social de un imaginario compartido, 1860-1930. En La sociedad del Salitre. Protagonistas, Migraciones, Cultura Urbana y Espacios Públicos, compilado por Sergio González, pp. 195-211. RIL Editores, Santiago, Chile.

Guajardo, G.

2007 Tecnología, Estado y ferrocarriles en Chile: 18501950. Fundación de los Ferrocarriles Españoles-Centro de Investigaciones Interdisciplinarias en Ciencias y Humanidades de la Universidad Nacional Autónoma de México, México DF.

Illanes, M. A.

1990 Azote, salario y ley: Disiciplinamiento de la mano de obra en la minería de Atacama (1817-1850). Proposiciones 19:90-122.

Illanes, M. A.

1992 La dominación silenciosa: Productores y prestamistas en la minería de Atacama, Chile. 1830-1860. Instituto Pofesional de Estudios Superiores Blas Cañas, Santiago, Chile.

Ladrón de Guevara, B.

2004 Patrimonio y territorio: Huellas del aprendizaje en tres años del Área de Patrimonio del Sistema Nacional de Información Territorial (SNIT). Revista Conserva 8:71-86.

Lorca, M.

2015 Minería y patrimonialización en el Norte Chico de Chile. De Re Metallica 25, en prensa.

Magán, J. M.

2002 La difícil definición y la escasa protección legislativa del patrimonio industrial. La situación legislativa estatal y autonómica. Gestión del Patrimonio Industrial en la Europa del siglo XXI, pp. 205-210. Congreso Vasco de Patrimonio Industrial, Bilbao, España.

Méo di, G.

1995 Patrimoine et territoire. Une parenté conceptuelle. Espaces et Société 78:15-34.

Nazer, R.

2000 El surgimiento de una nueva élite empresarial en Chile: 1830-80. En Minozare e culture imprenditoriali. Cile e Italia (secoli $X I X-X X$ ), editado por Franco Bonelli y Maria Rosaria Stabili, pp. 59-84. Carocci.

Ortega, L.

1981 Acerca de los orígenes de la industrialización chilena, 1860-1879. Nueva Historia 1 (2):3-54.

Ortega, L.

2005 Chile en ruta al capitalismo. Cambio, euforia y depresión 1850-1880. DIBAM-LOM-Centro de Investigaciones Diego Barros Arana, Santiago, Chile.

Ortega, L.

2010 La minería del cobre del Norte Chico (tradicional) y los medianos y pequeños productores en perspectiva histórica. 
Si somos americanos. Revista de estudios fronterizos. Vol. X (2):37-59.

Ortega, L.

2012 La crisis de la minería del cobre en el Norte Tradicional (Norte Chico, Chile) en la primera mitad del siglo XX y la decadencia de la Región de Coquimbo. Tiempo Histórico 4:43-66.

Pardo, C.

2011 Paisajes industriales e industrias para el turismo: Simbolismo patrimonial y alcance territorial. ROTUR, Revista de Ocio y Turismo 4:15-32.

Pederson, L.

2008 [1966] La industria minera del Norte Chico, Chile. Desde la conquista a 1963. RIL Editores, Santiago, Chile.

Pérez, L. y C. Parra

2004 Paisajes culturales: El parque patrimonial como instrumento de revalorización y revitalización del territorio. Teoría 13:9-24.

Pinto, J. y L. Ortega

1990 Expansión Minera y Desarrollo Industrial: Un caso de Crecimiento Asociado (Chile 1850-1914). Universidad de Santiago, Santiago, Chile.

Prats, L.

2003 Patrimonio + turismo $=$ ¿desarrollo $?$ PASOS, Revista de Turismo y Patrimonio Cultural 1 (2):127-137.

Prats, L.

2011 La viabilidad turística del patrimonio. PASOS, Revista de Turismo y Patrimonio Cultural 9 (2):249-264.

Rubio, $\mathrm{P}$.

2009 Aspectos de una minería periférica: El departamento de Chañaral y la explotación de cobre, 1885-1910. En Sociedad y Minería en el Norte Chico, 1840-1930, coordinado por Luis Ortega, Milton Godoy y Hernán Venegas, pp. 223-269. LOM Ediciones, Santiago, Chile.

Rubio, $\mathrm{P}$

2010 Auge y estancamiento del cobre en una región periférica. El departamento de Chañaral, 1880-1914. Si somos
Americanos. Revista de Estudios Transfronterizos X (2): 199-221.

Salazar, G.

1989 Labradores, peones y proletarios. Formación y crisis de la sociedad popular chilena del siglo XIX. Ediciones Sur, Santiago, Chile.

Sayago, C. M.

1973 [1874] Historia de Copiapó. Editorial Francisco de Aguirre, Buenos Aires.

Torrico, J. y E. Hernández.

2012 Paisaje e identidad territorial. Aproximación desde el caso de una provincia andaluza. XVII Congreso de Estudios Vascos: Innovación para el progreso social sostenible, pp. 473-486. Eusko Ikastuntza, Donostia.

Trachana, A.

2011 La recuperación de los paisajes industriales como paisajes culturales. Ciudades 14:189-212.

Treutler, $\mathrm{P}$.

1958 Andanzas de un alemán en Atacama: 1852-1858. Editorial del Pacífico, Santiago, Chile.

Valenzuela, L.

1995 Tres estudios sobre el comercio y fundición de cobre en Chile y en el mercado mundial. 1830-1880. Editorial Chile Ilustrado, Santiago, Chile.

Valenzuela, M.; A. Palacios y C. Hidalgo

2008 La valorización turística del patrimonio minero en entornos rurales desfavorecidos. Actores y experiencias. Cuadernos de Turismo 22:231-260.

Vergara, Á.

2011 "Cuando el río suena, piedras trae": Relaves de cobre en la bahía de Chañaral, 1938-1990. Cuadernos de Historia 35:135-151.

Yáñez, C.

2008 Patrimonialización del territorio y territorialización del patrimonio. Cuadernos de Arte de la Universidad de Granada 39:251-266.

\section{Notas}

1 Datos del censo 2002, proyectados al año 2006. En http:// www.subdere.cl/divisi\%C3\%B3n-administrativa-de-chile/ gobierno-regional-de-atacama/provincia-de-cha\%C3\%B1aral (17 abril 2015).

2 El Norte Chico, norte semiárido o norte tradicional posee una longitud aproximada de $750 \mathrm{~km}$, su límite norte es el río Salado, en la provincia de Chañaral, y el sur, la cuenca del río Aconcagua. Político-administrativamente la zona comprende las regiones de Atacama, Coquimbo y una pequeña parte de la Región de Valparaíso.

3 http://www.federacionminera.cl/2012/anglo-americaninvertiria-us30-millones-en-ampliacion-de-mantoverde/ (17 abril 2015).

4 http://static.pulso.cl/20130903/1812589.pdf (17 abril 2015).

5 http://www.nuevamineria.com/revista/codelco-planea-extender-en-20-anos-la-operacion-de-su-yacimiento-salvador/ (5 abril 2015).

6 Entre 1938 y 1989, Potrerillos y El Salvador vertieron al cauce natural del río Salado un total aproximado de 350 toneladas de residuos químicos y minerales tóxicos.
Esto significó que la bahía de Chañaral se embancara y solidificara, así como la desaparición de su ecosistema y el fin las actividades portuarias y pesqueras del lugar. Sin duda, este es el desastre ambiental más grande ocurrido en el país (Vergara 2011).

7 El material etnográfico con que se elaboró este trabajo fue recolectado durante enero de 2013 e implicó la visita al área de estudio y la realización de varias entrevistas a actores sociales pertenecientes al sector público, privado y asociativo.

8 Sol Pardo, Gerente PTI-CORFO Chañaral, entrevistada el 17 de enero de 2013.

9 Ambas iniciativas responden casi al exclusivo esfuerzo de Fidel Arancibia, gestor y emprendedor del turismo minero en Inca de Oro. Entrevistado el 16 de enero de 2013.

10 El informante que efectuó esta declaración solicitó anonimato. Entrevistado el 17 de enero de 2013.

11 Gabriel Manquez, Encargado del Departamento de Cultura y Turismo de la Municipalidad de Diego de Almagro, entrevistado el 16 enero de 2013. 